\title{
SOLDADOS DA PÁTRIA - HISTÓRIA DO EXÉRCITO BRASILEIRO (1889-1937)
}

\author{
Soldiers of the Patria: A History of the \\ Brazilian Army, 1889-1937 \\ Bruno Torquato Silva Ferreira*
}

\begin{abstract}
McCANN, Frank D. Soldados da Pátria - História do Exército Brasileiro (1889-1937). Tradução de Laura Teixeira Motta. São Paulo: Companhia das Letras, 2007. ISBN 9788535910841
\end{abstract}

Frank D. McCann é professor do Departamento de História da Universidade de New Hampshire e, nos anos 1960, como oficial da reserva do Exército americano, foi professor na Academia Militar de West Point. É autor de livros como Aliança Brasil-Estados Unidos (1937-1945) e A nação armada: ensaios sobre a história do Exército brasileiro. Teve passagens por universidades brasileiras como professor visitante, tendo sido também agraciado pelo governo brasileiro com alguns títulos. McCann vem se debruçando sobre os problemas concernentes à atuação política dos militares há mais de trinta anos e a sua produção acadêmica nesse período, ao que tudo indica, também se concentra nessa temática. Ultimamente vem se engajando em um projeto de desenvolvimento de uma base de dados biográficos sobre os oficiais do Exército brasileiro no século XX (Brazilian Army Officers Project) e na elaboração de uma biografia de Pedro Aurélio de Góes Monteiro (p. 621). Soldados da Pátria faz parte de um projeto maior cuja intenção é investigar a história da instituição militar terrestre brasileira até o começo da década de 1990 (p. 10).

Dois aspectos importantes da obra, no tocante aos processos de pesquisa e redação, merecem ser mencionados. O primeiro diz respeito ao uso abundante e original dos registros burocráticos produzidos pelo

\footnotetext{
* Doutorando em História pela Universidade Federal do Paraná (UFPR).
} 
comando militar no período, já que, no seu modo de ver, um estudo sobre a formação da oficialidade do Exército deveria incluir a estrutura, a doutrina, os equipamentos e o treinamento dos homens dessa instituição como objetos de análise, ${ }^{1}$ material este ainda pouco explorado pelos pesquisadores brasileiros. Sobre os estudos relacionados à década de 1920 no Brasil, o próprio McCann é quem alerta aos interessados:

A história de um Exército, dada a complexidade da instituição, requer um enfoque amplo. Além disso, não deve se ocupar apenas dos vencedores; precisa também falar de quem perdeu e por quê. Apesar da importância das rebeliões, há mais na história do Exército (p. 290).

As rebeliões em si revelam muito das características culturais dos brasileiros naquela época; as amizades foram fatores não desprezíveis para a aderência ou não a um lado (revoltado) ou outro (legalista) nas vésperas dos sucessivos movimentos. Muitas vezes, era o posicionamento da maioria da guarnição o que determinava o comportamento dos oficiais (p. 361-362). Por outro lado, mesmo os legalistas não delatavam os seus colegas conspiradores quando convidados a tomar parte nos movimentos (p. 622). Portanto, "conversar, escrever e até mesmo tramar eram tolerados até que alguma ação ocorresse" (p. 410). Além disso, muitos simpatizantes das conspirações deixavam de tomar parte nos movimentos sediciosos por lealdade aos seus comandantes legalistas: "Cabe ressaltar que os oficiais brasileiros não juravam obediência à Constituição, e sim a seus superiores, de modo que os laços pessoais tinham papel importante na manutenção da disciplina", pois se tratava de um sistema "acentuadamente paternalista, influenciado pelas ligações pessoais de amizade" (p. 373). De fato, a pátria estava acima da Constituição, do gabinete, do imperador ou do presidente: "O Exército brasileiro foi e ainda é um baluarte contra as forças centrífugas regionalistas" (p. 11).

1 Ainda resta saber até que ponto o Exército foi uma instituição controlada de alto a baixo pela oficialidade. Chama atenção também o uso expressivo e constante de relatórios diplomáticos e de adidos militares para alcançar compreensão a respeito de aspectos da socialização, das condições de vida, da profissionalização e do ambiente político no interior do Exército. 
Talvez refletindo sobre suas próprias limitações analíticas a esse respeito, o autor comentou: "Muitos estrangeiros tinham dificuldade para perceber, e ainda mais para aceitar, a importância da amizade na vida política pública brasileira" (p. 649). Contudo, essa tradição de conciliação chegou ao fim a partir da segunda metade da década de 1930, sobretudo após 1935, quando os sargentos e demais praças passaram a ser alvo de brutal repressão, sem falar dos constantes expurgos e ameaças de expurgos tornados constantes a partir de 1937, utilizados para chantagear e manter na linha os ocupantes da base hierárquica da instituição.

Alguns comentários são reveladores acerca da maneira como alguns americanos compreendem a realidade brasileira, em que pesem os incômodos que podem causar aos brasileiros mais ciosos ou mesmo aos padrões nacionais de cientificidade no tocante às humanidades. $\mathrm{O}$ episódio de 15 de Novembro, por ser pouco conhecido e investigado, foi descrito como um dos "aspectos bizarros da história brasileira moderna" (p. 28) ou "A história do Exército brasileiro é mais bem compreendida como um reflexo da complexa, intrincada e às vezes contraditória cultura nacional" (p. 9). O autor parece supor que não exista cultura "contraditória". ${ }^{2}$

Em segundo lugar, chama a atenção do leitor mais atento a bibliografia utilizada, que demonstra existir nos Estados Unidos uma historiografia brasileira à parte, com a qual, diga-se de passagem e salvo exceções, a historiografia produzida no Brasil parece manter muito pouco contato, embora a recíproca não seja verdadeira. Temas como a proclamação da República, o conflito de Canudos, a Revolta da Vacina, o conflito do Contestado, a Revolução de 1930, a economia brasileira nas primeiras décadas do século XX, entre outros assuntos, foram e são largamente debatidos em universidades americanas e, em alguns casos, as pesquisas resultantes desses debates apresentam dados inteiramente originais. ${ }^{3}$

2 Do mesmo modo, McCann revelou inocência metodológica ao expor sua intuição de que Vargas pretendia reconstitucionalizar o país em 1932 e só não colocou em prática esse projeto em função do movimento paulista ocorrido em julho daquele mesmo ano baseado unicamente nas evidências contidas no diário "secreto" do político brasileiro, publicado apenas em 1995, pois, de acordo com o autor, "agora sabemos o que ele estava dizendo a si mesmo naquela época” (p. 419).

3 A respeito do conflito ocorrido em Canudos no final do século XIX, merece destaque a informação de que o beato Antônio Conselheiro mantinha estreitas relações clientelísticas com alguns coronéis locais, membros do clero e inclusive com o próprio governador da Bahia na época (p. 64, verificar especialmente a nota 66). 
O autor, desde o começo, anuncia seu rompimento com as análises que interpretam as rebeliões militares como reflexos da política civil ou mesmo de determinismos classistas. Nesse sentido, segue a trilha já palmilhada por autores brasileiros e brasilianistas, como Edmundo Campos Coelho, José Murilo de Carvalho, John Schulz e Alfred Stepan. Seguindo os rastros desses mesmos autores, também indica que seu intuito inicial de entender o comportamento dos militares brasileiros no período de 1964-1985 levou-o "constantemente" de volta ao período 1889-1937, o qual começou a ver como "a sementeira de acontecimentos posteriores" (p. 10).

Não concorda, por outro lado, com a tese do "poder moderador" de Alfred Stepan (p. 14-15) e, neste ponto, se aproxima mais uma vez das abordagens de Carvalho e Coelho. Conclusão do autor: "O Exército não se tornou o moderador na década de 1890; seu poder era muito precário e muito cooptado. Antes da década de 1930, o Exército não possuía vontade institucional, a doutrina ou a capacidade para tal papel” (p. 14). A unidade doutrinária na formação dos oficiais seria alcançada apenas décadas depois, com a homogeneização da sua formação (p. 251). Acontece que na década de 1920 muitos sargentos foram comissionados em postos de oficiais, o que parece ter dificultado essa propalada unificação doutrinária. Sem unificação doutrinária, como esperar que agissem de forma ordenada, coesa e coerente?

Nesse sentido, o autor aponta a importância da ESAO e da ECEME $^{4}$ na unificação doutrinária do Exército nos escalões médios e altos da organização no decorrer do século XX (p. 270). Por outro lado, na década de 1920 essa unidade ainda era incipiente, razão pela qual o autor atribui à falta de unidade doutrinária uma das principais causas da "disposição [dos jovens oficiais] de desrespeitar a hierarquia e rebelar-se" (p. 276). Para McCann, o Exército começou a se tornar moderador apenas a partir de 1937: "Vargas abriu a porta, e os generais entraram" (p. 547).

O grande caráter instrumental do Exército se revelou quando ele foi acionado para "manter na linha as massas, ou pessoas comuns" (p. 19). Assim podem ser compreendidos episódios como Canudos e Contestado, além da própria repressão aos comunistas e esquerdistas na década de 1930. Além

4 Escola de Aperfeiçoamento de Oficiais e Escola de Comando e Estado-Maior do Exército, respectivamente. Atualmente constituem cursos de pós-graduação equiparados aos níveis de mestrado e doutorado pelo Ministério da Educação. 
disso, foi o principal instrumento de projeção política do Estado-nacional brasileiro. Esta leitura se estende para além dos limites cronológicos do Estado Novo, não obstante a autonomia institucional alcançada pelo Exército, que lhe potencializou um intervencionismo mais atuante (p. 552-553).

O Exército brasileiro, nesse último período, trilhou um caminho institucional que o transformou de uma força miliciana em uma organização de caráter nacional e relativamente ramificada pelo território brasileiro. Desempenhou importante papel civilizador - no sentido eliasiano - e constituiu uma espécie de ponta de lança do Estado no que diz respeito às necessidades de integração territorial e desenvolvimento de valores identitários relacionados a esse espaço, principalmente após o advento do serviço militar obrigatório. A esse respeito, destaca-se a importância de intelectuais militares da estirpe de Alfredo Taunay e Euclides da Cunha como grandes formuladores da identidade nacional.

Do etno-historiador (?) Anthony F. C. Wallace, McCann incorporou as categorias analíticas política dos apetites e política da identidade para se referir aos dois polos que embasaram a conduta política da oficialidade brasileira nos 30 primeiros anos da República (p. 17). A última se refere aos movimentos sociais e suas reivindicações, que podem colocar em xeque o domínio oligárquico e a primeira, por sua tonalidade clientelística, contribuía para a manutenção do status quo (p. 17-18). Nem mesmo o eterno legalista Estevão Leitão de Carvalho teria se mostrado imune aos apetites (p. 373). Com efeito, de acordo com McCann, o tenentismo foi um misto de política das identidades e dos apetites (p. 18). No entanto, reconhece que a principal luta dos tenentes nos anos 1920 era mais pelo controle do Exército do que por qualquer outro motivo (p. 339).

Foi uma época de fortes dissensões internas: clivagens horizontais e verticais opunham oficiais entre si e contra praças. Desse modo, o autor se propõe a explicar as razões internas das explosões de violência corriqueiras na evolução institucional do Exército, sobretudo nas décadas de 1910, 1920 e 1930. São acontecimentos que revelam profundidades estruturais e, por isso, sua explicação não é autoevidente, como foi o episódio das cartas atribuídas a Arthur Bernardes contra Hermes da Fonseca (p. 279). Entre as razões do descontentamento da oficialidade estavam questões profissionais vinculadas à insatisfação com a organização política do país, como promoções atrasadas, atrasos nos soldos, falta de equipamentos, inadequação 
dos armamentos, a estrutura política excludente, conflitos latentes com os membros da Missão Militar Francesa, entre outros.

Assim sendo, McCann demonstra percepção acurada ao relacionar a explosão das rebeliões no período focado por suas investigações aos conflitos e problemas intraorganizacionais, alguns por razões comezinhas. Nesse sentido, reconhece, por exemplo, que a principal luta dos tenentes nos anos 1920 era mais pelo controle do Exército do que por qualquer outro motivo (p. 339). ${ }^{5}$ Tratava-se de um conflito geracional, que tinha seus fundamentos nos bloqueios à progressão profissional dos mais jovens e nas diferenças de formação. Dessa maneira, consegue iluminar e oferecer uma explicação plausível acerca da linha de experiência política que se iniciou com a crise conhecida como Questão Militar e que atravessou todo o primeiro terço do século XX até a crise dos anos 1930, que redundou na inauguração do Estado Novo em 1937. Ao mesmo tempo, a análise da experiência política da oficialidade do Exército nas décadas de 1920 e 1930 é usada como fator explicativo das condições que levaram ao regime de 1964-1985 (p. 12).

Muito ainda precisa ser respondido sobre o envolvimento militar na política brasileira, mas essa obra se revela salutar, instigante e incontornável para quem se interessa pelo entendimento do papel desempenhado pela oficialidade do Exército na construção do Estado nacional e da própria nacionalidade, entre outros aspectos. Sua obra merece atenção dos historiadores brasileiros, sobretudo porque, em que pesem as irresponsabilidades dos relativismos atualmente em voga, constitui um alento motivador para aqueles que ainda se ocupam com a história de verdade, e não com representações oníricas.

Recebido em maio de 2012. Aprovado em julho de 2012.

5 Ainda resta saber até que ponto o Exército foi uma instituição controlada de alto a baixo pela oficialidade. Chama atenção também o uso expressivo e constante de relatórios diplomáticos e de adidos militares para alcançar compreensão a respeito de aspectos da socialização, das condições de vida, da profissionalização e do ambiente político no interior do Exército. 